\title{
Cálculo da Transferência de cargas em complexos envolvendo Sulfeto de Hidrogênio e Gases nobres
}

Alan Leone de Araújo Oliveira(PG) ${ }^{1}$, Henrique Vieira Rivera Vila (PQ) ${ }^{1}$, Luiz Guilherme Machado de Macedo $^{2}$ Ricardo Gargano(PQ ${ }^{1}$

kurumimleone@gmail.com ${ }^{1}$,gargano@unb.br ${ }^{3}$

\footnotetext{
${ }^{1}$ Instituto de Física, Universidade de Brasília, 70910-900. Brasília, Brasil

${ }^{2}$ Instituto de Ciências Biológicas, Universidade Federal do Pará,
}

Palavras-chave: Hidrogênio, Sulfeto, Argônio

O conhecimento dos efeitos de transferência de carga em interações intermoleculares fracas (tipo van der Waals) envolvendo moléculas hidrogenadas e gases nobres, podem auxiliar na descrição completa e detalhada da natureza da ligação de hidrogênio [1]. Tal relação requer uma descrição do equilíbrio crítico das componentes de interação eletrostática, transferência de carga, indução, dispersão e troca. O presente trabalho consiste em realizar um estudo detalhado da transferência de carga entre complexos formados por moléculas hidrogenadas e gases nobres, tais como $\mathrm{H}_{2} \mathrm{~S}-\mathrm{Ng}$, com $\mathrm{Ng}=\mathrm{He}$, $\mathrm{Ne}, \mathrm{Ar}, \mathrm{Kr}$, Xe e Rn. A transferência de carga é também crucial para desenvolver modelos para a descrição dos campos de força que operam em sistemas complexos de interesse tecnológico e biológico. O deslocamento de carga (DC) é dado ao longo de uma dada direção "z", expresso pela equação:

$$
\Delta q(z)=\int_{-\infty}^{\infty} d x \int_{-\infty}^{\infty} d y \int_{-\infty}^{z} \Delta \rho\left(x, y, z^{\prime}\right) d z^{\prime}
$$

onde $\Delta \rho$ é a diferença de densidade eletrônica. Em resultados preliminares realizados para o complexo $\mathrm{H}_{2} \mathrm{~S}-\mathrm{Ar}$, determinamos o DC ao longo do eixo " $\mathrm{z}$ " descrito na figura abaixo. A partir dessa figura, foi possível observar uma pequena densidade de eleétrons fluindo do átomo de argônio para a molécula de sulfeto de hidrogênio.

Com estes cálculos espera-se conhecer com detalhes a partição das forças intermoleculares envolvidas nestes tipos de sistemas. Tais resultados estão em um excelente acordo com os disponíveis na literatura, consolidando os métodos e estratégias adotados no presente trabalho.

\section{Agradecimentos:}

Este trabalho foi apoiado pela CAPES, CNPq e FAPDF.

\section{Referências}


a)

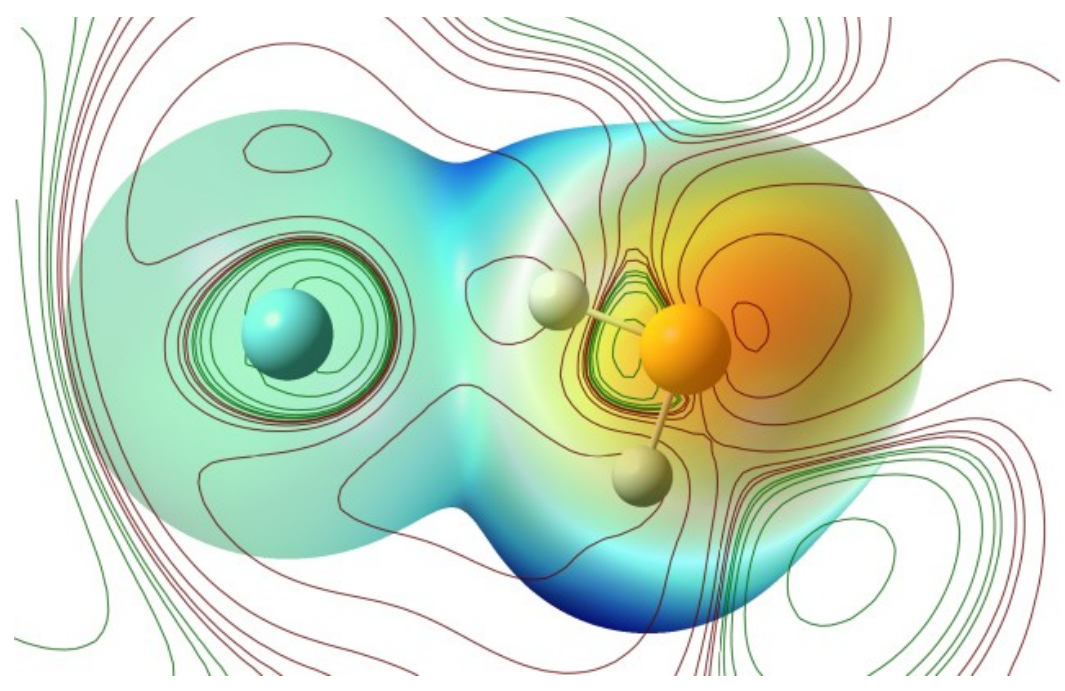

b)

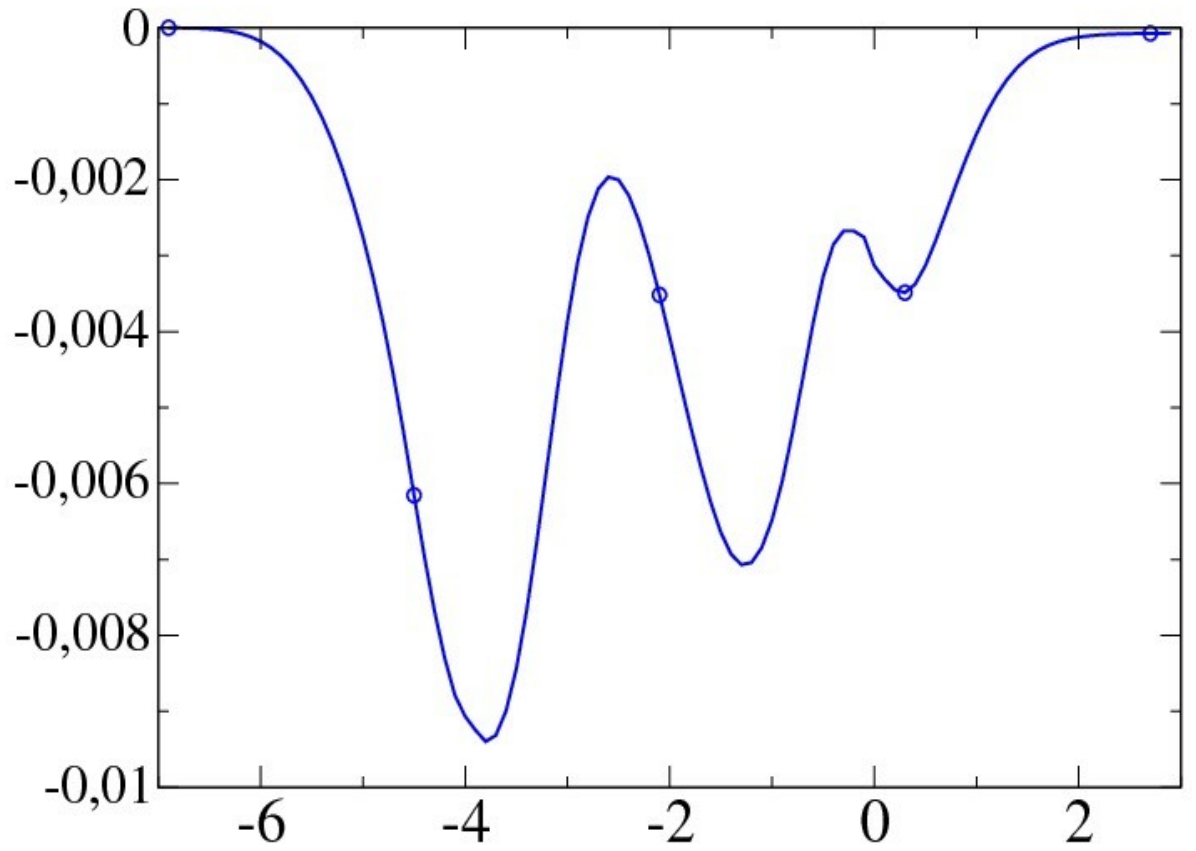

a)Transferência de carga do átomo de argônio para a molécula $\mathrm{H}_{2} \mathrm{~S}$ considerando o complexo $\mathrm{H}_{2} \mathrm{~S}-\mathrm{Ar}$ na conformação de mínima energia, onde a origem do eixo-z encontra-se no átomo de enxofre; b) Gráfico do deslocamento de carga em cada ponto ao longo do eixo-z. 